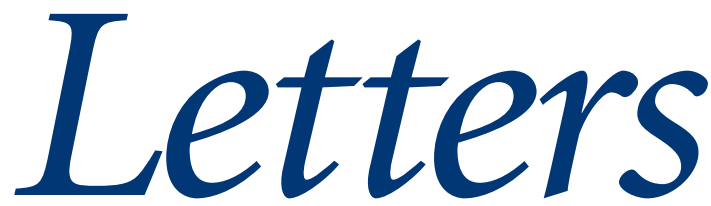

All letters are subject to editing and may be shortened. Letters should be sent to the BJGP office by e-mail in the first instance, addressed to

journal@rcgp.org.uk (please include your postal address). Alternatively, they may be sent by post as an MS Word or plain text version on CD or DVD. We regret that we cannot notify authors regarding publication. Letters not published in the Journal may be posted online on our Discussion Forum. For instructions please visit: http://www.rcgp.org.uk/bjgp-discuss

\section{MRSA carriage}

Mulqueen et al' describe the prevalence of MRSA carriage among GPs in the West of Ireland and note accurately the lack of data available on prevalence rates of MRSA in the community. Having made the same observation, I conducted a study within a general practice community in rural northwest Ireland last year. All consecutive attendees at the surgery over a 2-week period in December 2006 were invited to participate until a sample of 114 was obtained. Data on previously identified risk factors for MRSA carriage, such as recent hospital admission, antibiotic use in the last 3-6 months, ${ }^{2}$ and having a chronic disease,,$^{2-4}$ was collected on participants and a single nasal swab was taken from the anterior nares. Only one case of MRSA carriage was identified giving a point prevalence of $0.9 \%(95 \% \mathrm{Cl}=0.25 \%$ to $5.57 \%)$. That subject had none of the categorised risk factors. We did not test the GPs serving this area, but the setting of our study is very similar to your published study in which the nasal carriage rate among GPs was $7 \% .{ }^{1}$ In the literature there were three similar population studies to be found from the UK - all of which report a comparable prevalence figure. $(0.8-1.5 \%)^{3,5,6}$ If these two Irish studies tell us anything it is that we are more likely to convey MRSA to our patients than the other way around, whether this is from our high rate of carriage or our high rate of prescribing, we would do well to be constantly aware of our primary ethical principle and first do no harm.

\section{Sarah Smyth}

Registrar, Donegal Specialist Training

Programme in General Practice.

E-mail: sarahmsmyth@yahoo.com

\section{REFERENCES}

1. Mulqueen J, Cafferty F, Cormican M, et al. Nasal carriage of meticillin-resistant Staphylococcus aureus in GPs in the West of Ireland. Br J Gen Pract 2007;
57(543): 811-813.

2 Hidron AI, Kourbatova EV, Halvosa JS, et al. Risk factors for colonization with methicillin-resistant Staphylococcus aureus (MRSA) in patients admitted to an urban hospital: emergence of community-associated MRSA nasal carriage. Clin Infect Dis 2005; 41(2): 159-166.

3. Grundmann H, Tami A, Hori S, et al. Nottingham Staphylococcus aureus population study: prevalence of MRSA among elderly people in the community. BMJ 2002; 324(7350): 1365-1366.

4. Jernigan JA, Pullen AL, Partin C, Jarvis WR. Prevalence of and risk factors for colonization with methicillin-resistant Staphylococcus aureus in an outpatient clinic population. Infect Control Hosp Epidemiol 2003; 24(6): 445-450.

5. Maudsley J, Stone SP, Kibbler CC, et al. The community prevalence of methicillin-resistant Staphylococcus aureus (MRSA) in older people living in their own homes: implications for treatment, screening and surveillance in the UK. J Hosp Infect 2004; 57(3): 258-262.

6. Abudu L, Blair I, Fraise A, Cheng KK. Methicillinresistant Staphylococcus aureus (MRSA): a communitybased prevalence survey. Epidemiol Infect 2001; 126(3): 351-356.

10.3399/bjgp08X277041

\section{Gaelic}

I write in response to your appeal in December's Journal for any readers who might be familiar with the language of the Garden of Eden to supply a translation for the concluding solicitudes in Neville Goodman's last column.

The first two are quite staightforward, meaning 'blessings with you' and 'thank you' respectively. The first is commonly used to bid farewell. The third one is slightly more complicated and literally translated means 'good providence to you'.

To appreciate those statements you need an awareness of the culture as well as the language that inspired them. As luck is not a Hebridean concept at all there is no word in Gaelic for it. Most people in the Western Isles still believe that there is a certain order to life, and death, and who in our profession could argue with that. So in wishing people well for the future as you part company we cannot say 'good luck' but rather express the wish that providence might be good to them.

Neither of course do we believe very much in Christmas as it is celebrated nowadays, as it has more to do with the birth of Santa Claus some 100 years ago than with a certain event in Bethlehem some 2000 years ago.

So I will refrain from wishing you and your readers a Merry Christmas as it will be well past by the time this is published anyway. I will however wish all those who read your Journal and especially my colleagues on the Panel of Examiners a prosperous and happy New Year as they undertake the transition from old to nMRCGP. So far providence has been on their side. Lets hope it remains so.

Leis gach durachd (With every good wish).

\section{John Smith}

GP, Stornoway, Western Isles.

E-mail: JSmithHolm@aol.com

\section{REFERENCE}

1. Goodman N. A long, strange trip. Br J Gen Pract 2007; 57(545): 1003.

10.3399/bjgp08X277050

\section{Sexual enquiry in older people}

Sexual wellbeing is likely to be an important aspect in the management of older mental health patients as increasing age ${ }^{1}$ and mental illness ${ }^{2}$ can both adversely affect sexual practice and satisfaction. With this in mind, we explored the expectations and attitudes of people over age 65 years with mental illness towards sexual healthcare with an anonymous, cross-sectional postal survey. Participants (mean age 78 years) were patients affiliated with old-age psychiatric services at St Charles Hospital, with $64 \%$ having diagnoses of either dementia or depression. A total of 139 surveys were posted, 30 were returned (22\% response rate) and six people complained.

We found that most responders (18, 